\title{
Analysis on the Change of Ecosystem Service Value of National Forest Park and Its Coupling with Social Economy in the Past 40 Years
}

\author{
Yuan Wang ${ }^{1}$, Yinan Yang ${ }^{1}$, Jing $\mathrm{Li}^{1}$, Minyan $\mathrm{Zhao}^{2}$, He Gong ${ }^{2}$, \\ Li Wang ${ }^{1}$, Lixia Zhao ${ }^{3,4,5}$, Mei Huang ${ }^{2 *}$ \\ ${ }^{1}$ College of Geography and Tourism, Anhui Normal University, Wuhu, China \\ ${ }^{2}$ Institute of Geographic Sciences and Natural Resources Research, CAS, Beijing, China \\ ${ }^{3}$ East China Sea Environment Monitoring Center, State Oceanic Administration, Shanghai, 201206, China \\ ${ }^{4}$ Key Laboratory of Marine Ecological Monitoring and Restoration Technology, MNR, 201206, China \\ ${ }^{5}$ Key Laboratory of Ocean Space Resource Management Technology, MNR, Hangzhou, 310012, China
}

Received: 6 May 2021

Accepted: 30 August 2021

\begin{abstract}
National Forest Park is the highest hierarchy of nature reserve system in China, which provides enormous ecosystem service values (ESV). However, few researchers focus on its coupling with socioeconomics. Here we analyze temporal and spatial variation of ecosystem service value of National Forest Parks (FESV) under the transformation of forest policy and market demand at national scale, and spatial dynamics of coupling coordination degree between FESV and socio-economics at different stage. The results show that temporal variation of FESV exhibit obvious phase characteristics, with the third phase has the largest growth rate (50.71). The spatial evolution of FESV has gone through a process from point to area, mainly showing aggregation distribution concentrated in Heilongjiang, Sichuan and Tibet, accounting for $32.08 \%$ of nationwide total ESV. The coupling coordination degree between FESV and socio-economic develop from maladjusted to transitional and then to coordinated stage, which has reached 0.83 at the fourth stage. By the end of the fourth stage, up to 20 provinces develop over transitional stage, but 17 provinces are still at maladjusted stage. These results indicate that further research and management should focus on how to balance socio-economic development and the construction of National Forest Parks.
\end{abstract}

Keywords: National Forest Park, ecosystem service value, coupling coordination degree model

e-mail: huangm@igsnrr.ac.cn 


\section{Introduction}

Forest Park is one of the major forms of nature conservation and tourism in China. With rapidly increasing demand on ecological space and protecting/ restoring deteriorated nature ecosystem, forest parks, especially National Forest Parks, have become vanguards of eco-civilization construction. National Forest Park is the highest level in China's forest park system, which is vital in building national ecological security barriers. In past 40 years, National Forest Parks in China have undergone tremendous changes in terms of quantity, quality and spatial distribution. In 1982, first National Forest Park was established in Zhangjiajie, and there are 881 National Forest Parks being approved by the end of 2017. Except for enormous landscape resources and raw materials, National Forest Parks also provide various ecological services especially for environmental and social health. Assessing temporal and spatial evolution of ecosystem service values of National Forest Park (FESV) in China and their coupling coordination degree with socio-economic is essential for supporting further construction and optimizing spatial arrangement of National Forest Parks. Besides, detangling the relationship between FESV and socio-economics is also important for balancing the development of National Forest Park and local socio-economic demand.

Ecosystem services represent the benefits directly or indirectly derived from ecosystem functions, including the products and services provided by ecosystems [1]. Costanza estimated the global total ecosystem service values (ESV) at \$33 trillion using the equivalent factor method [1]. Since then, some approaches have been developed to counting forest ESV, such as functional value approach [3], direct market approach [3], alternative market approach [4], virtual market approach [5], and ecological modeling approach [6]. Xie et al. [7] classified China's ecosystem service into 9 categories based on Costanza's study, revised the table of ecosystem service values per unit area of different terrestrial ecosystems, and assessed regional ESV in China [8]. Thereafter, more and more studies focus on accounting for the ESV of forest in China $[9,10]$.

Recently, studies about FESV focus more on the relationship between ecosystem services and socioeconomic in the framework of social-economic-natural complex ecosystem. For example, Michael et al. [11] explored the service provisioning and social feedback loops of ecosystem services in social systems and ecosystems. Lagbas et al. [12] studied the willingness to pay of different gender, age and income groups for forest park ecosystem services in Arroceros Forest Park, Philippines. Aschenbrand et al. [13] connected socio-scientific landscape research with ecosystem services to deal with management conflicts in National Forest Parks. Gao et al. [14] studied the social ESV in forest parks using the method proposed by Sherrouse et al. [15]. He et al. [16] took Wuyishan National Forest Park as an example, proposing a model based on science, policy and practice to evaluate the importance of ecosystem services to local community residents; Besides, based on the social-ecological system analysis framework of interest cognition, they studied the ecosystem meaning cognition, interest definition and potential management rules evaluation of multiple stakeholders in national parks [17].

Studies on forest parks mainly focus on evaluating the cultural value [18], recreational value [19], and social value [20] of forest parks at local scale. However, there are fewer studies about the relationship between FESV and socio-economics, such as spatio-temporal dynamics of FESV and their coupling with socio-economics at national scale. In order to fill this gap, we intend to analyze the coupling coordination degree between FESV and socio-economic, detangling the relationship between National Forest Park construction and socioeconomic, and explore the coupling mechanism between ecology and society based on policy transformation. Our research could provide a useful reference for future development strategy formulation, spatial layout optimization, and human-land coupling development of forest parks. Besides, it can enrich theory of the relationship between ecosystem services and socioeconomic interactions in nature reserves.

\section{Material and Methods}

\section{FESV Calculating}

In this paper, we used the method proposed by Costanza et al. [1] (Eq. 1) and selected the ESV equivalent per unit area developed by Xie et al. [8] (Table 1) to calculate the FESV in China. The calculation formula was as follows,

$$
F E S V=\sum_{i=1}^{n} P_{i} \times A
$$

where: $P_{i}$ is the unit price of ecosystem services per unit area, because National Forest Parks are mainly forest ecosystems, only forest types are chosen for land use types (the same below). $i$ represents each ecosystem service function respectively; $A$ is the park area.

Since ecosystem biomass largely affects the magnitude of ecosystem services, the unit price of ecosystem services was revised with reference to the approach proposed by Xie et al. [7]:

$$
P_{i}=(b / B) p p_{i}
$$

where: $B$ is the average biomass per unit area of primary ecosystem type in China, referring to the research results of Fang et al. [21], taking $87.80 \mathrm{t} / \mathrm{hm}^{2}$; $p p_{i}$ is the ecosystem service price per unit area of National Forest Parks in China; Using the natural grain method, the annual average net profit of three types 
of grain (rice, wheat and corn) in China from 1990 to 2017 was $1606.65 \mathrm{CNY} / \mathrm{hm}^{2}$, which was regarded as a standard equivalent factor of ESV. Combined with the value equivalent of ecosystem services per unit area (Table 1), we get the price $p p_{i}$ of ecosystem services per unit area (Table 1). $b$ is the biomass of the National Forest Park ecosystem, calculated as following,

$$
b=\partial N P P / \beta
$$

where: the NPP unit is $g c / \mathrm{m}^{2}$, obtained based on the simulation results of the AVIM2 model [22-24]. $\partial$ is the conversion coefficient between biomass and productivity, and the average value of 19.67 was taken according to the research results of Whittaker et al. [25], Liu et al. [26], Feng et al. [27], and Li et al. [28]. $\beta$ is the conversion coefficient when converting NPP to dry matter mass, and 0.5 was taken according to the usual international practice.

\section{Coupling Coordination Degree Model}

In order to reveal the relationship between FESV and socio-economics, we calculate their coupling coordination degree [29]. Firstly, we construct a socioeconomic evaluation index which includes 6 indicators, such as urbanization rate, GDP, residents' consumption level, local fiscal expenditure, population density and forest park tourism income. The urbanization rate is an important indicator of social development and progress. GDP is an important index to measure the scale of economic development. The consumption level of residents reflects the demand for National Forest Park, and the tourism income of Forest Park reflects the construction effect of National Forest Park. The construction and development of National Forest Parks need the support of funds and other resources, while the local financial expenditure reflects the strength of local support for the development of National Forest Parks. Data of urbanization rate, GDP, consumption level, local fiscal expenditure and population density are from China Statistical Yearbook. Tourism income of forest parks comes from the Forestry Science and Technology Information Institute of China Academy of Forestry (http://forest.ckcest.cn/sd/si/zgslgy.html). The net profit per hectare of three major grain crops (rice, wheat and maize) in China is derived from Summary of National Agricultural Product Cost-benefit Data, National Compendium of Agricultural Product Cost-benefit Data and China Rural Statistical Yearbook.

The coupled coordination degree model is calculated as follow,

$$
\begin{gathered}
U_{1}=\sum_{i=1}^{m}\left(w_{a j} \cdot X_{a i j}\right) \\
U_{2}=\sum_{i=1}^{n}\left(w_{b j} \cdot X_{b i j}\right) \\
C=\sqrt{\frac{U_{1} \times U_{2}}{\left(\frac{U_{1}+U_{2}}{2}\right)^{2}}} \\
D=(C \times T)^{\frac{1}{2}} \\
T=x U_{1}+y U_{2}
\end{gathered}
$$

...where: $U_{1}$ and $U_{2}$ are the comprehensive evaluation values of socio-economic and FESV; $m$ and $n$ are the number of socio-economic and FESV dimensions respectively; $w_{a j}$ and $w_{b j}$ represent the weight of each index of $U_{1}$ and $U_{2}$ respectively, and are determined by entropy method [30]. The distribution of $X_{a i j}$ and $X_{b i j}$

Table 1. Unit area forest ecosystem service value equivalent and price.

\begin{tabular}{|c|c|c|c|}
\hline Primary classification & Secondary classification & Value equivalent & Price $\left(\mathrm{CNY} / \mathrm{hm}^{2}\right)$ \\
\hline \multirow{3}{*}{ Supply services } & Food production & 0.25 & 405.68 \\
\cline { 2 - 4 } & Raw material production & 0.58 & 931.86 \\
\cline { 2 - 4 } & Water Supply & 0.30 & 481.99 \\
\hline \multirow{3}{*}{ Support services } & Soil conservation & 2.32 & 3731.44 \\
\cline { 2 - 4 } & Maintaining nutrient circulation & 0.18 & 285.18 \\
\cline { 2 - 4 } & Biodiversity & 2.12 & 3398.06 \\
\cline { 2 - 4 } Reconciliation services & Gas Regulation & 1.91 & 3064.68 \\
\cline { 2 - 4 } & Climate regulation & 5.71 & 9169.94 \\
\cline { 2 - 4 } & Purifying the environment & 3.67 & 2687.12 \\
\hline \multirow{2}{*}{ Cultural services } & Hydrological regulation & 3.74 & 6000.83 \\
\hline
\end{tabular}


Table 2. Coupling coordination degree classification.

\begin{tabular}{|c|c|c|}
\hline \multirow{3}{*}{ Classification } & Coupling coordination degree & Type \\
\hline \multirow{3}{*}{ Coordinated category } & $0.90-1.00$ & High quality coordination \\
\cline { 2 - 3 } & $0.80-0.89$ & Good coordination \\
\cline { 2 - 3 } & $0.70-0.79$ & Intermediate coordination \\
\cline { 2 - 3 } & $0.60-0.69$ & Primary coordination \\
\hline \multirow{3}{*}{ Transitional category } & $0.50-0.59$ & Grudging coordination \\
\cline { 2 - 3 } & $0.40-0.49$ & On the verge of maladjustment \\
\hline \multirow{3}{*}{ Maladjusted category } & $0.30-0.39$ & Mild maladjustment \\
\cline { 2 - 3 } & $0.20-0.29$ & Moderate maladjustment \\
\cline { 2 - 3 } & $0.10-0.19$ & Severe maladjustment \\
\cline { 2 - 3 } & $0.00-0.09$ & Extreme maladjustment \\
\cline { 2 - 3 } & & \\
\hline
\end{tabular}

represents the $j$-th value of the $i$-th index of $U_{1}$ and $U_{2}$. In order to eliminate different dimensions, the maximum-minimum method is used for data standardization [31]; $C$ is the coupling degree between FESV and socio-economics. $T$ is a harmonic index, $x$, $y$ are harmonic coefficients, assuming that FESV is as important as socio-economic, so take 0.5 each; $D$ is the coupling coordination degree of FESV and socioeconomics, which is divided into 10 levels with reference to the study of Liao et al. [32] (Table 2).

\section{National Forest Park Development Stage Division}

The development of National Forest Parks in China is influenced by national policies and market changes showing obvious stage characteristics. In order to better understand the development pattern of forest parks, the developing trajectory of National Forest Parks was divided into four stages referring to the study of Zhao et al. [33]: the first stage (1982 1991), which was the

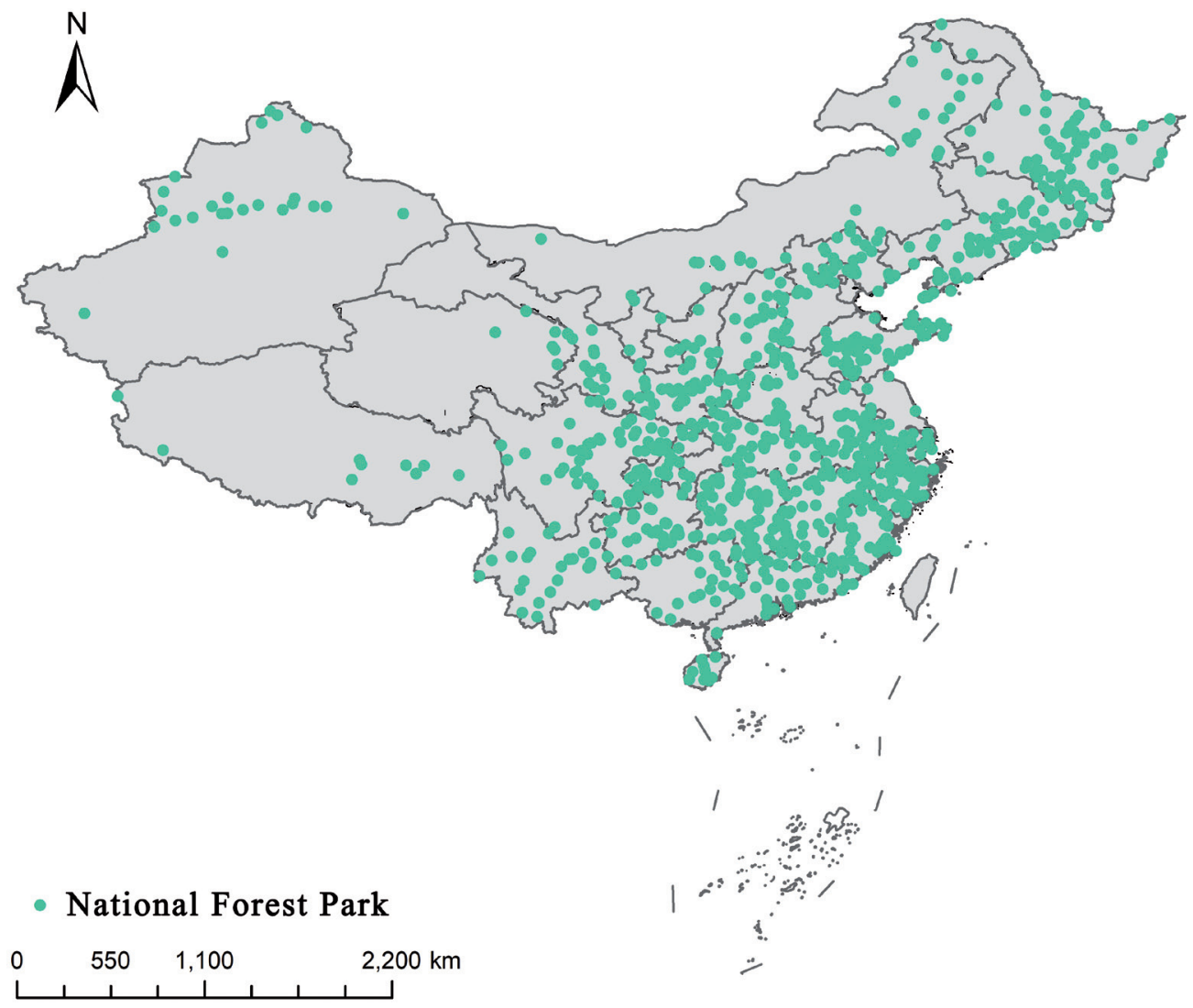

Fig.1. National Forest Parks in China. 
initial stage of National Forest Park development in China with a small scale. A total of 17 National Forest Parks were built nationwide, with an average annual increase of 1.78. In the second stage (1992 1999), 287 National Forest Parks were built in this stage, with an average annual increase of 35.88. In the third stage (2000 2007), the number of National Forest Parks show explosive growth with increasing national consumption level especially on nature tourism. 351 National Forest Parks were built in this stage, with an average annual increase of 43.88. In the fourth stage (2008 2017), 226 National Forest Parks were built in this stage, with an average annual increase of 22.60. By the end of 2017, the number of National Forest Parks in China has reached 881, covering an area of 11970700 hectares. This paper selects all National Forest Parks (Fig. 1) established from 1982 to 2017. The datasets of the National Forest Park including establishment time and area are derived from the official website of the State Forestry and Grassland Administration (http://www. forestry.gov.cn/).

\section{Results}

\section{Stage Characteristics of FESV}

FESV in China showed a rapid growth trend during 1982 2017 (Fig. 2). It grew from CNY 0.26 billion in 1982 to CNY 921.28 billion in 2017, with an average growth of 26.32 billion CNY/a and an average annual growth rate of $26 \%$. Besides, FESV in China presented obvious stage characteristics under coupled effects of forest policy transformation and socio-economic market demands change.

The first stage. Under the state's leadership, state-owned forest farms have attempted market- oriented reforms to develop forest tourism through the construction of national forest parks, and as a result, their ESV has begun to develop. FESV of Zhangjiajie National Forest Park established in 1982 was CNY 0.26 billion. Thereafter, due to the uncertain effect of the forest tourism and the long-term ideological solidification of planned economy, the construction speed of National Forest Parks slowed down. Correspondingly, the growth rate of FESV kept slow or even stagnant. Such state was broken in 1991, as FESV rose to CNY17.22 billion, and this stage realized the breakthrough of FESV from 0 to 1 . However, the extent of National Forest Park is quite small, with an average annual ESV of CNY 4.08 billion and the lowest growth rate (1.67) in four stages.

The second stage. Owing to the development of market economy and increasing tourism demand, the construction of National Forest Parks accelerated a lot. In 1992, 136 National Forest Parks were approved with FESV surging to CNY 121.69 billion, up by $606.55 \%$ compared with 1991 . The profit-driven nature of market capital has greatly excavated the value of recreation and other service functions of National Forest Parks, which also drives the growth of FESV. The growth rate of ESV at this stage reaches 29.01, which is 17.33 times of the first stage. In second stage, National Forest Parks have achieved great crosscutting development. By 1999, FESV has reached CNY 287.25 billion.

The third stage. With the implementation of weekend system and golden-week system, the development of National Forest Parks ushered its climax. FESV rose to CNY 337.32 billion in 2000, and reached CNY 647.05 billion in 2007. The growth rate of FSEV reached 50.71 presenting the fastest increasement in past 20 years. However, in late years of this stage, construction of National Forest Parks has changed from

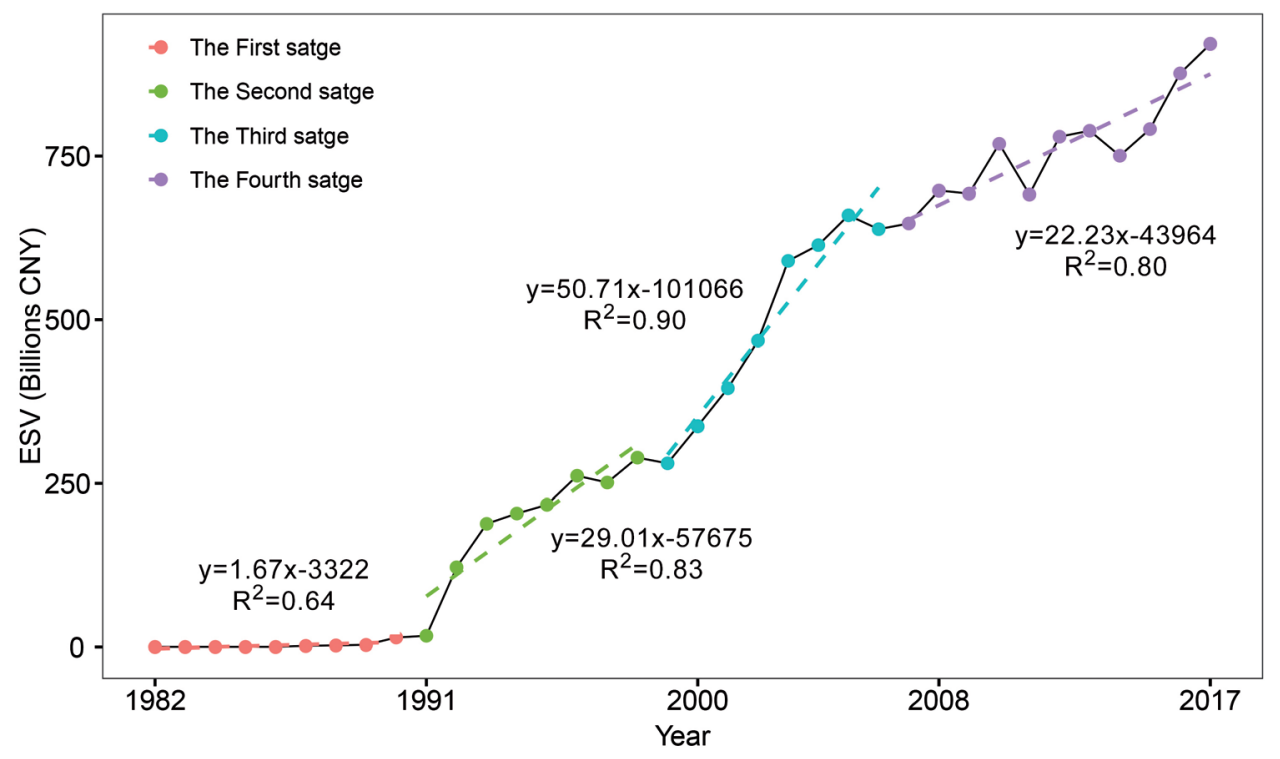

Fig. 2. Interannual change of FESV. 
utilization-oriented to protection-oriented, which also slowed down the growth of FESV.

The fourth stage. FESV increased from CNY 697.15 billion in 2008 to CNY 921.28 billion in 2017, but the growth rate (50.71 and 22.23 in 2008 and 2017 respectively) decreased ca. $43.84 \%$ comparing with previous stage. The decreased growth rate of FESV attributed to the change in driven force from economicoriented 'tourism development driven' to ecological protection-oriented 'ecological function space optimization driven'. With the establishment of nature reserve system, spatial optimization rather than amount increment of National Forest Parks may contribute much more to the growth of FESV.

\section{Spatial Evolution of FESV at Different Stages}

Along with staged development of National Forest Parks, spatial distribution of FESV develop from singlecore mode to multi-point mode, then to dual-corespread mode, and finally to dual-core-deepening mode (Fig. 3). According to the growth pole theory,

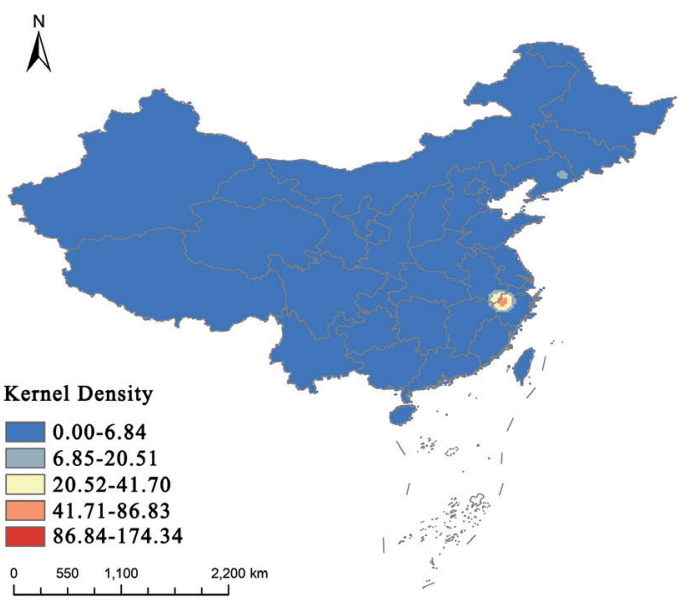

a.The First Stage

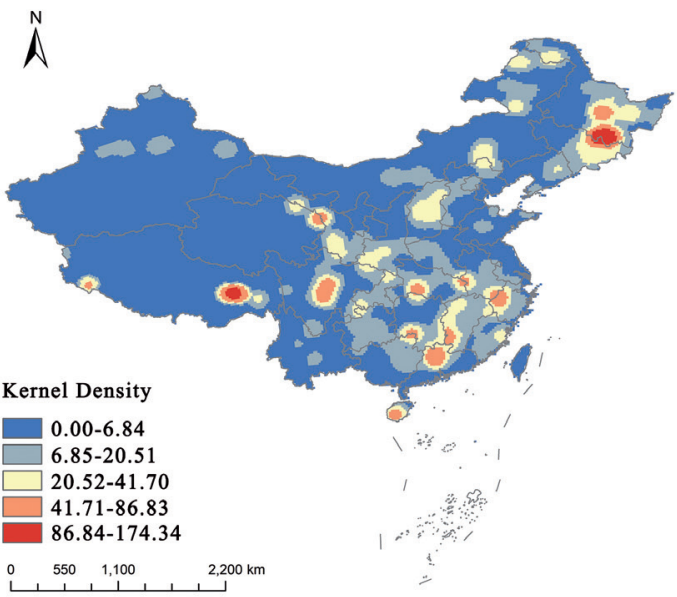

c.The Third Stage advantages of capital, technology and talents make a region easier to form a growth pole. The development of National Forest Parks highly relies on regional economic foundation. The location advantage of Yangtze River Delta makes it to be the first growth pole of FESV spatial distribution (Fig. 3a). With the rapid growth of FESV and vast territory of China, it is difficult for a single growth pole in the Yangtze River Delta to radiate enough area to meet the demand of value growth. Therefore, in areas with relatively developed socioeconomic and enormous forest resources, such as the junction of Hunan and Guangdong, Hunan and Hubei, Hebei and Shanxi, Heilongjiang and Jilin, multiple growth poles emerged forming a multi-point pattern of FESV (Fig. 3b). In the third stage (Fig. 3c), FESV spread radially from multiple growth poles. At the same time, with the universal improvement of socio-economics and promotion of supporting policies, the regions with forest resources advantages are more likely to become new polar cores of FESV. At this stage, two polar cores emerged in the junction region of Heilongjiang and Jilin and the southeast region of Qinghai Tibet

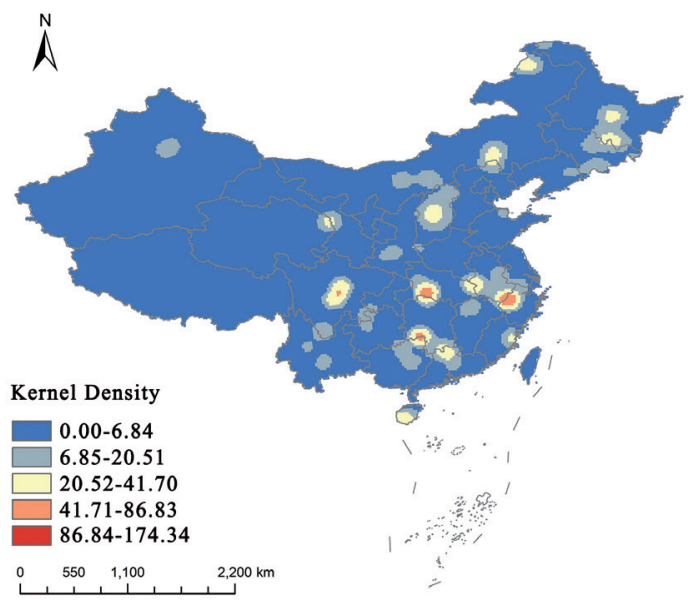

b.The Second Stage

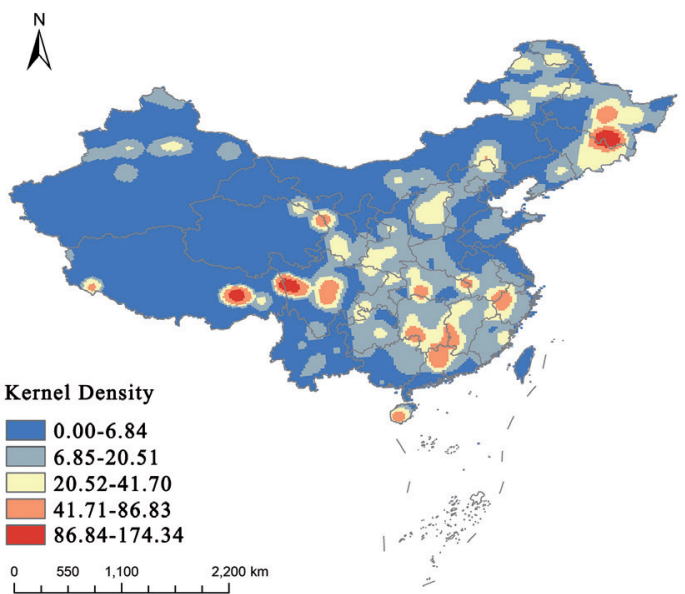

d.The Fourth Stage

Fig. 3. Kernel density of FESV. 
Plateau respectively, forming dual core spread pattern. To the fourth stage, the value diffusion effect began to weaken with deceased spatial spread speed of ESV (Fig. 3d). Meanwhile, the value polarization effect began to appear. FESV of those regions around growth pole has been strengthened, especially two polar cores emerged in previous stage present more obvious agglomeration, especially the south polar core.

\section{Coupling Analysis of FESV and Socio-Economic at Different Stages}

In the past 40 years, FESV has been greatly improved, and its coupling coordination with socioeconomic has changed from extremely maladjusted recession to high-quality coordinated development. The coupling degree and coordination degree of FESV and socio-economic increased from 0.05 and 0.06 in 1982 to 0.99 and 0.95 in 2017 with an increase of $1979.59 \%$ and $1375.10 \%$, respectively (Table 3 ).

In the first stage, because National Forest Park is still in the initial stage with low ESV, there is a huge gap between FESV and socio-economic level. Specifically, comprehensive evaluation value of FESV is only $2.59 \%$ of that of socio-economic, and coupling between them is quite weak $(0.22)$, so is the coordination degree $(0.12)$. Besides, coupling coordination between FESV and socio-economic belongs to the severe maladjustment decline type of environmental lag.

In the second stage, comprehensive evaluation value of FESV rose to 0.25 due to its rapid increase, with an annual change of 11.79 times of that in the first stage. In contrast, socio-economic development is relatively stable. Affected by market economy reform, comprehensive evaluation value of socio-economics even declined slightly (0.16). Due to reduced gap between FESV and socio-economic level, their coupling degree increases to 0.97 presenting high coupling characteristics. However, their coordination is still low (0.44), which belongs to the economic lag type and is on the verge of maladjustment recession.

In the third stage, the comprehensive evaluation value of FESV and socio-economic have increased, and their coupling degree maintains a high level above 0.90 , while the coordination degree also rises to 0.61 into the coordinated development state. However, FESV has a higher annual average increment of comprehensive evaluation value comparing with socio-economics. The coupling type between FESV and socio-economic is the economic-lagged primary coordinated development category, because FESV presented the fastest growth in this stage, but socio-economics developed rapidly after the reform of market economy.

In the fourth stage, all relative evaluation indicators increased a lot, including the comprehensive evaluation value of socio-economics (0.58), its coupling degree (0.98) and coordination degree (0.83) with FESV. Actually, FESV and the socio-economics have reached coordinated development coupling coordination level. Such transition is attributed to following two aspects, on the one hand, the focus of National Forest Parks construction has transferred from quantity to spatial optimization and high-quality development; On the other hand, the socio-economic level has ushered in a qualitative leap after the market economy reform in previous stage.

\section{Spatial Evolution Analysis of FESV and Socio-Economic Coupling}

In past 40 years, coupling coordination degree between FESV and socio-economics present significant spatio-temporal heterogeneity (Fig. 4). In the first stage, because most provinces have not yet started to construct National Forest Parks, the coupling coordination degree is generally low. Thereinto, Zhejiang

Table 3. Coupling and coordination degree of FESV and socio-economic.

\begin{tabular}{|c|c|c|c|c|c|}
\hline \multicolumn{2}{|c|}{ Stage } & The fourth & The third & The second stage & The \\
\hline \multirow{2}{*}{$\begin{array}{c}\text { Comprehensive } \\
\text { socio-economic evalua- } \\
\text { tion value }\end{array}$} & Average value & 0.58 & 0.24 & 0.16 & 0.16 \\
\hline & Annual variation & 0.05 & 0.02 & 0.00 & 0.00 \\
\hline \multirow{2}{*}{$\begin{array}{l}\text { Comprehensive } \\
\text { evaluation value of FESV }\end{array}$} & Average value & 0.84 & 0.59 & 0.25 & 0.00 \\
\hline & Annual variation & 0.02 & 0.04 & 0.02 & 0.00 \\
\hline \multirow{2}{*}{ Coupling } & Average value & 0.98 & 0.91 & 0.97 & 0.22 \\
\hline & Annual variation & 0.01 & 0.00 & -0.01 & 0.06 \\
\hline \multirow{2}{*}{$\begin{array}{c}\text { Coupling and } \\
\text { coordination degree }\end{array}$} & Average value & 0.83 & 0.61 & 0.44 & 0.12 \\
\hline & Annual variation & 0.02 & 0.02 & 0.01 & 0.02 \\
\hline \multirow{2}{*}{ Type characteristics } & Coupling system type & $\begin{array}{c}\text { Good } \\
\text { coordination }\end{array}$ & $\begin{array}{l}\text { Primary } \\
\text { coordination }\end{array}$ & $\begin{array}{l}\text { On the verge of } \\
\text { maladjustment }\end{array}$ & $\begin{array}{c}\text { Severe } \\
\text { maladjustment }\end{array}$ \\
\hline & Characteristics & $\begin{array}{l}\text { Economic } 1 \\
\text { agging type }\end{array}$ & $\begin{array}{l}\text { Economic } \\
\text { lagging type }\end{array}$ & $\begin{array}{l}\text { Economic } \\
\text { lagging type }\end{array}$ & $\begin{array}{l}\text { Environmental } \\
\text { lagging type }\end{array}$ \\
\hline
\end{tabular}


and Liaoning province belong to good coordinated development category and grudging coordination category respectively, and the other provinces are in the coupling of environmental lag type maladjustment category (Fig. 4a). In the second stage, with the explosive development of National Forest Parks in many provinces, the coupling coordination between FESV and socio-economic has been effectively improved. The number of provinces at maladjusted state has dropped from 28 to 6 , meanwhile the number of transitional and coordinated development provinces rose from 2 and 1 to 14 and 11, respectively (Fig. 4b). In the third stage, the number of maladjusted provinces (5) and coordinated development provinces (6) decreased to a certain extent, and the number of transitional provinces (20) increased, forming hump-shaped distribution. Thus, the overall situation of coupling coordination degree between FESV and socio-economic is basically

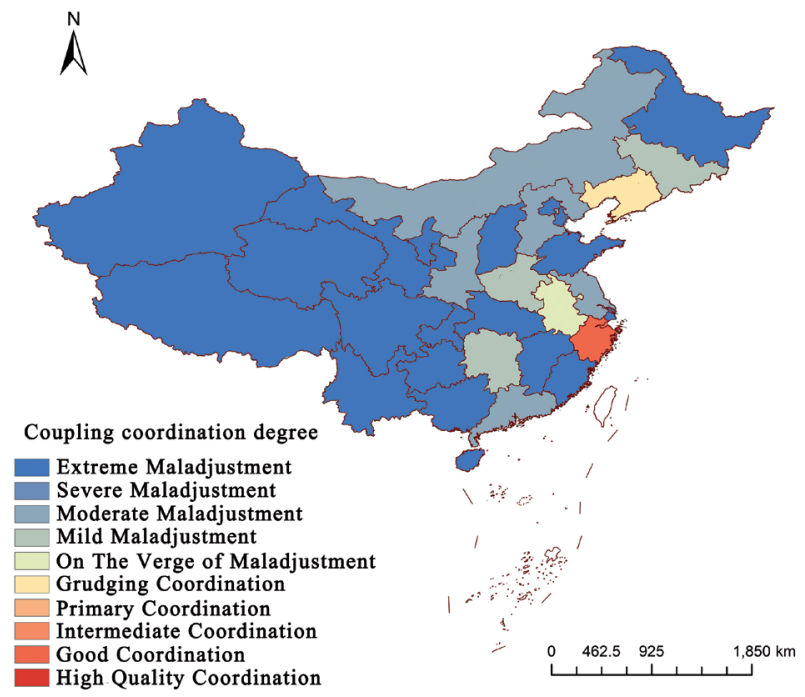

a.The First Stage

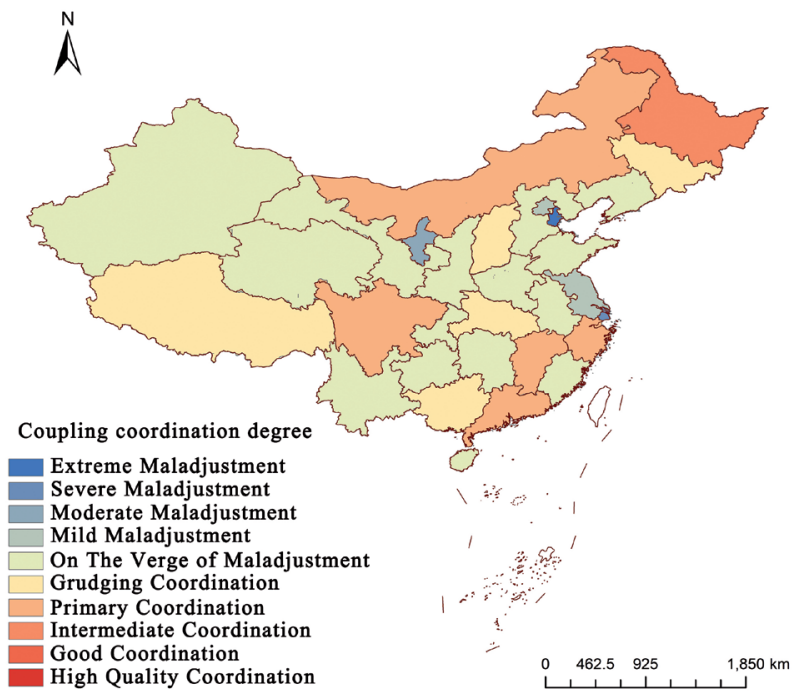

c.The Third Stage fixed at national scale (Fig. 4c). In the fourth stage, such hump-shaped distribution was still maintained, in which the number of coordinated development provinces increased slightly (7), the number of maladjustment provinces decreased slightly (4), and the number of intermediate transitional provinces took up the largest proportion (Fig. 4d).

After nearly 40 years of development, the coupling coordination of FESV and socio-economic in each province has been improved (Fig. 4). Coordinated development provinces are mainly distributed in Heilongjiang and Inner Mongolia, Sichuan, Hubei, Hunan, Jiangxi, Guangdong and Zhejiang. Among them, the comprehensive evaluation value of FESV in Heilongjiang province is the highest. However, due to limited socio-economic level, the coupling coordination degree between FESV and socio-economic is only in the intermediate coordinated development category.

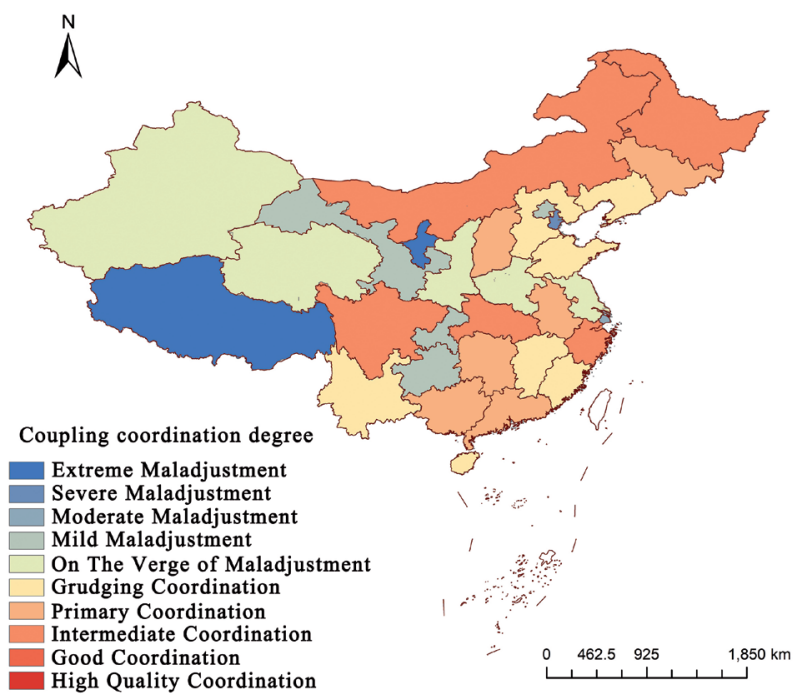

b.The Second Stage

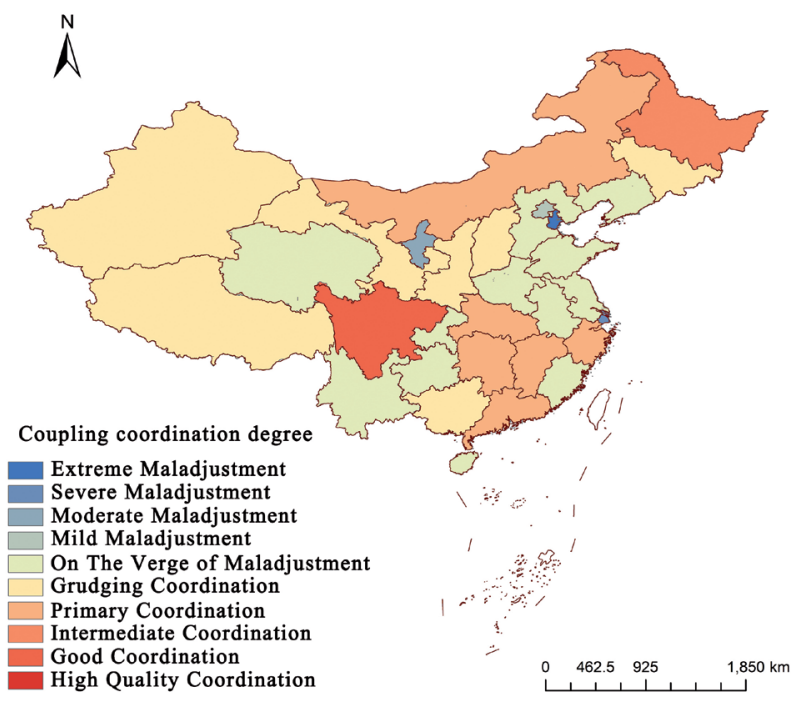

d.The Fourth Stage

Fig. 4. Spatio-temporal evolution of FESV and socio-economic coupling. 
In contrast, higher comprehensive evaluation value of FESV and socio-economic in Sichuan province makes it be in the good coordinated development category. And other provinces have just entered the coordinated development level. The maladjusted development provinces are mainly concentrated in Beijing, Tianjin, Shanghai and Ningxia with small administrative areas, all of them belong to the environmental-lagged maladjusted decline type. Thereinto, small area and poor geographical environment of Ningxia lead to the maladjustment between its socio-economic and FESV. However, in Beijing, Tianjin and Shanghai, rapid economic growth lead to fast expansion of urban construction area, which has seriously squeezed the area of forest ecosystems. Among the transitional provinces, Tibet and Xinjiang provinces are in economic-lagged transitional state. In specifically, due to the vast land and sparse population, their comprehensive evaluation values of FESV are higher and their comprehensive evaluation values of socio-economic are lower, which restrict them achieving coordinated development. Other transitional provinces, such as Qinghai, Jiangsu, Liaoning, Anhui, Yunnan, Henan, Hainan, Chongqing, Hebei, Fujian, Guizhou, Shandong, Shaanxi, Gansu, Shanxi, Guangxi, Jilin and so on, are all at environmental lagged transitional coordinated development state, because of their time-lagged FESV development comparing to socio-economics development.

\section{Discussion}

National forest policy and socio-economic demand are the dominant factors affecting spatio-temporal evolution of FESV and their coupling coordination. Temporal changes of FESV present obvious periodic characteristics with the changes of national policies and socio-economics. The construction of National Forest Parks began in the Middle-Lower Yangtze Plain with more developed economy and dense population, which mainly concentrated in the east of Hu Huanyong line. The coupling coordination of FESV and socioeconomics has transferred from maladjusted to transitional and then to coordinated development. Macro-control of policy and micro-regulation of market are important approaches to affect the coordinated development of FESV and socio-economics.

With increasing conflict on demand of ecological tourism and limited territory for construction of National Forest Parks, it's urgent to develop highquality ecological space and promote their spatial influence. Hence, the following suggestions were put forward for promoting the coupling coordination between FESV and socio-economics. Firstly, it's essential to promote appeal of National Forest Parks in western of China to alleviate tourism pressure in eastern developed regions. Secondly, large number of small high-quality forest parks may compensate for lack of large-scale National Forest Parks in maladjusted developed urban. Thirdly, to improve the evenness of FESV, more stakeholders should involve in construction and protection of National Forest Parks through carbon trading, ecological compensation, public service, joint construction of community, etc.

Different from the existing quantitative evaluation of FESV, this paper focuses on exploring the coupling relationship between FESV and socio-economics. The construction and development of National Forest Parks deeply affected by policy transformation, their intrinsic intention is providing functions and services to human beings. Therefore, the change and development of FESV have a great relationship with the socio-economics. Our research provides scientific support for guiding the construction and protection of National Forest Parks in the future. Coupling coordination degree model is a good approach to detangle the coupling relationship between FESV and socio-economic development under different policy backgrounds. However, due to the subjectivity of the selected evaluation model index, certain deviations may be inevitable in different index systems.

\section{Conclusion}

1) In the past 40 years, FESV has made great progress and formed a certain scale. In 2017, FESV reached CNY 921.28 billion, which is 3489.70 times of 1982. In the third stage, the growth rate is the fastest, with a slope of 50.71 .

2) Affected by the transformation of national forest policy and the change of market demand in different stages, the spatial characteristics of FESV experienced a process of deepening from point to surface. In 2017, three provinces with the highest ESV (Heilongjiang, Sichuan and Tibet) accounted for $32.08 \%$ of the total FESV of China. As a result, the spatial distribution of FESV is uneven and unbalanced, showing obvious regional differences.

3) From 1982 to 2017, FESV and socio-economic development transferred from maladjustment recession to coordinated development, and the coupling coordination degree increased from 0.12 in the first stage to 0.83 in the fourth stage, an increase of 7 times. Among them, the coupling coordination degree of the fourth stage has the largest annual growth rate of 0.023 , followed by the third stage $(0.022)$, the accelerated development stage (0.01) and the first stage (0.02). Besides, the number of FESV and socio-economic coordinated development provinces rose from 1 to 7 , the number of transitional provinces rose from 2 to 20 , and the number of maladjustment provinces declined from 28 to 4. Great achievements were made in the construction and protection and of National Forest Parks, and the embodiment of FESV, but it is still in a critical transitional period. 


\section{Acknowledgments}

This research was supported by the Category A Strategic Leading Science and Technology Specialty of Chinese Academy of Sciences (XDA23100200, XDA20010202), National Natural Science Foundation for Youth Scientists of China (NO.42106171), Open Fund of Key Laboratory of Marine Ecological Monitoring and Restoration Technology, MNR (NO. MEMRT202111) and Open Fund of Key Laboratory of Ocean Space Resource Management Technology, MNR (KF-2021-107).

\section{Conflict of Interest}

The authors declare no conflict of interest.

\section{References}

1. COSTANZA R., D'ARGE R., GROOT R.D., FARBER S., GRASSO M., HANNON B., LIMBURG K., NAEEM S., O'NEILL R.V., PARUELO J. The value of the world's ecosystem services and natural capital. Nature, 387 (15), 253, 2017.

2. CHOLHO S., WOO-KYUN L., HYUN-AH C., JAEUK K., SEONG W.J., JOON S.K. Spatial assessment of ecosystem functions and services for air purification of forests in South Korea. Environmental Science \& Policy, 63, 27, 2016

3. COSTANZA R., GROOT R.D., SUTTON P., PLOEG S.D., ANDERSON S.J., KUBISZEWSKI I., FARBER S., TURNER R.K. Changes in the global value of ecosystem services. Global Environmental Change, 26, 152, 2014.

4. TILAHUN M., DAMNYAG L., ANGLAAERE L.C.N. The Ankasa Forest Conservation Area of Ghana: Ecosystem service values and on-site REDD plus opportunity cost. Forest Policy and Economics, 73, 168, 2016.

5. NORDÉN A., CORIA J., JÖNSSON A.M., LAGERGREN F., LEHSTEN V. Divergence in stakeholders' preferences: Evidence from a choice experiment on forest landscapes preferences in Sweden. Ecological Economics, 132, 179, 2017.

6. HU Z.N., YANG X., YANG J.J., YUAN J., ZHANG Z.Y. Linking landscape pattern, ecosystem service value, and human well-being in Xishuangbanna, southwest China: Insights from a coupling coordination model. Global Ecology and Conservation, 27, 2351, 2021.

7. XIE G.D., LU C.X., LENG Y.F., ZHENG D., LI S.C. Ecological assets valuation of the Tibetan Plateau. Journal of Natural Resources, 18 (2), 189, 2003 [In Chinese].

8. XIE G.D., ZHANG C.X., ZHANG L.M., CHEN W.H., LI S.M. Improvement of the evaluation method for ecosystem service value based on per unit area. Journal of Natural Resources, 30 (8), 1243, 2015 [In Chinese]..

9. HUANG L.S., WANG B., NIU X., SONG Q.F. Spatial pattern of the ecosystem service function of forests in Jinan City. Acta Ecological Sinica(in Chinese), 39 (17), 6477, 2019.

10. SHI X., WANG T., CHEN K., CAO X., DENG J. Reliability analysis and cumulative impact assessment of forest ecosystem services: a case study of Jilin province, China IEEE Access, 2021, DOI:10.1109/ACCESS.2021.3071123.

11. NASSL M., LOFFLER J. Ecosystem services in coupled social-ecological systems: Closing. Ambio, 44 (8), 737, 2015.

12. LAGBAS, ARTHUR J. Social valuation of regulating and cultural ecosystem services of Arroceros Forest Park: A man-made forest in the city of Manila, Philippines. Journal of Urban Management, 8 (1), 159, 2019.

13. ASCHENBRAND E., MICHLER T. Linking SocioScientific Landscape Research with the Ecosystem Services Approach to Analyze Conflicts About Protected Area Management - The Case of the Bavarian Forest National Park. Modern Approaches to the Visualization of Landscapes, Edler D., Jenal C., Kuhne O., Eds., Springer Fachmedien Wiesbaden: Wiesbaden, Germany, 403, 2020.

14. GAO Y., LIU K., MA Q., LI Y., FAN Y.N., LI X.Q., GU C. Assessment of social value of ecosystem services based on SolVES model and visitor's preference: A case study of Taibai Mountain National Forest Park. Chinese Journal of Ecology, 36 (12), 3564, 2017 [In Chinese].

15. SHERROUSE B.C., SEMMENS D.J., ANCONA Z.H., BRUNNER N.M. Analyzing land-use change scenarios for trade-offs among cultural ecosystem services in the Southern Rocky Mountains. Ecosystem Services, 26, 431, 2018.

16. HE S.Y., SU Y., WANG L., CHENG H. Taking an ecosystem services approach for a new national park system in China. Resources, Conservation \& Recycling, 137, 136, 2018.

17. HE S.Y., SU Y., CHENG H.G., WANG L., MIN Q.W. Value analysis and management measures of national parks based on multi-stakeholder selection: A case of Wuyishan National Park. Journal of Beijing Forestry University (Social Sciences, in Chinese), 18 (1), 93, 2019.

18. PENG W.T., LIU W.Q., CAI W.B., WANG X., HUANG Z., WU C.Z. Evaluation of ecosystem cultural services of urban protected areas based on public participation GIS (PPGIS): A case study of Gongqing Forest Park in Shanghai, China. Journal of Applied Ecology, 30 (2), 439, 2019 [In Chinese]

19. DENG Z.M., HUANG X.J., ZHU J.J. Theoretical validity of CVM on assessment of the recreation value in forest scenic areas: A case study of Fuzhou National Forest Park. Science Silvae Sinicae, 54(8), 133, 2018 [In Chinese].

20. WANG Y., FU B.T., LV Y.P., YANG K., CHE Y. Assessment of the social values of ecosystem services based on SolVES model: A case study of Wusong Paotaiwan Wetland Forest Park, Shanghai, China. Journal of Applied Ecology, 27 (6), 1767, 2016 [In Chinese].

21. FANG J.Y., LIU G.H., XU S.L. Biomass and net production of forest vegetation in China. Acta Ecologica Sinica, 16 (5), 497, 1996 [In Chinese].

22. SUN X., HUANG M., WANG G. The asynchronous response of carbon gain and water loss generate spatiotemporal pattern of WUE along an elevation gradient in southwest China. Biogeosciences Discussions, 10, 1, 2016.

23. HUANG M., HOU J., TANG X.L., HAO M. Response of vegetation and soil carbon accumulation rate for China's mature forest on climate change. Journal of Plant Ecology, 40 (4), 416, 2016 [In Chinese].

24. HUANG B.G., YANG J., HUANG M. The spatiotemporal variation of net primary productivity of vegetation in Xinjiang in recent 55 Years. Desert and Oasis Meteorology, 12 (4), 90, 2018 [In Chinese]. 
25. WHITTAKER R.H., LIKENS G.E. Carbon in the biota. Virginia: Springfield, 24 (30), 281, 1973.

26. LIU S.R., XU D.Y., WANG B. Impacts of climate change on productivity of forests in China I. geographic distribution of actual productivity of forests in China. Forest Research, 6 (6), 633, 1993 [In Chinese].

27. FEN Z.W., WANG X.K., WU G. Biomass and productivity of forest ecosystems in China. Beijing: Science Press. 1999.

28. LI G.F., REN H. Biomass and net primary productivity of the forests in different climatic zones of China. Tropical Geography, 24 (4), 306, 2004 [In Chinese].

29. CHENG X., LONG R., CHEN H., LI Q. Coupling coordination degree and spatial dynamic evolution of a regional green competitiveness system - A case study from China. Ecological Indicators, 104, 489, 2019.

30. ZHAO D., LI C., WANG Q., YUAN J. Comprehensive evaluation of national electric power development based on cloud model and entropy method and TOPSIS: A case study in 11 countries. Journal of Cleaner Production, 277, 123190, 2020.

31. YU L.P. Research on the influence mechanism of index standardization method on science and technology evaluation. Information Studies: Theory \& Application, $\mathbf{4 3}$ (12), 54, 2020 [In Chinese].

32. LIAO Z.B. Quantitative judgment and classification system for the coordinated development of environment and economy - A case study of the city group in the Pearl River Delta. Tropical Geography, 19 (2), 3, 1999 [In Chinese].

33. ZHAO M.Y., CHEN X.F. The development and management of forest parks in China. Science Silvae Sinicae, 52 (1), 118, 2016 [In Chinese]. 
